\title{
Micro Sourcing Strategic Framework for Low Income Group
}

\author{
Noor Habibah Arshad \\ Department of Information Systems \\ Faculty of Computer and Mathematical Sciences, \\ University Teknologi MARA, \\ Shah Alam, Malaysia
}

\begin{abstract}
The role of ICTs among poor people and communities has increased tremendously. One of the ICT industries - the micro sourcing industry - has been identified as one of a potential industry to help increase income for the poor in Malaysia. Micro sourcing is an effective way to accomplish tedious tasks at a faster rate. It involves large projects that are broken down into micro tasks. These micro tasks are welldefined and then distributed to a group of workers. The objective of this study is to develop the strategic framework of micro sourcing to generate income for the low income group. Four methods were used to gather information for this study. The methods used were documentation and literature reviews, focus group meetings, workshops and interviews. Based on the analysis of the current scenario of local micro sourcing industry, strategic framework was developed based on the five Strategic Thrusts identified. The Strategic Thrusts are harnessing demand side (job providers) of domestic and international market; platform capacity and capability building; leverage and utilise existing infrastructure; uplift and enhance capability of the supply side (micro workers); and instruments to expedite growth of local micro sourcing industry. The Strategic Framework is intended to provide strategic direction at national level to all stakeholders; to highlight key areas that need to be addressed in order to grow a sustainable micro sourcing industry in the country; and to serve as a guideline in the implementation of programs and plans related to micro sourcing industry development
\end{abstract}

Keywords-Capability building; expedite growth; harnessing demand; platform capacity; strategic thrusts

\section{INTRODUCTION}

The role of developing countries and poor people and communities as consumers and producers of ICTs is evolving. There is growing interest in developing countries as potential growth markets for ICT goods and services. In response, ICT producers are adjusting their products as well as business models to target low-income consumers. More resources are allocated to find ways to reach the "bottom of the pyramid" [1]. Improving mobile access - partly as a result of cheaper imports of technology - at increasingly affordable rates, and new service models are facilitating access for people without large or predictable incomes. This development has allowed for greater involvement of enterprises from developing countries in ICT-related innovation processes [2].

This study is conducted by researchers from Universiti Teknologi MARA, Shah Alam, Malaysia in collaboration with Malaysia Development Corporation (MDeC) and fully funded by Malaysia Ministry of Finance.

\author{
Siti Salwa Salleh, Syaripah Ruzaini Syed Aris, \\ Norjansalika Janom, Norazam Mastuki \\ Faculty of Computer and Mathematical Sciences, \\ Faculty of Accountancy University Teknologi MARA, \\ Shah Alam, Malaysia
}

ICTs can also strengthen internal information systems for those (predominantly growth-oriented) enterprises that own PCs and are able to make effective use of computer-based applications. There is further evidence that ICTs can provide other benefits involving the strengthening of social and human capital such as enhancement of skills, increased selfconfidence, increased participations of women, empowerment, and security against income loss. ICT use helps cement or even accentuate existing power relations and inequalities. ICT can reinforce the market position and power of existing trading intermediaries, whose actions may not impact positively on the livelihoods of the poor. Finally, the role of ICTs might be more limited in local value chain systems (particularly of subsistence based enterprises) that rely heavily on pre-existing, informal and culturally rooted communication where the exchange of valued information is by means of personal contact.

The extent to which technologies are available and used by the poor varies a great deal, with mobile phones and radio appearing as the most widely diffused and Internet-connected PCs (and especially with a broadband connection) the least. Beyond availability, the uptake of certain technologies by the poor also depends on the needs and capabilities of potential users. What matters is whether people have the access to what they want and need, not that they have access to technologies which are identical to other people with different needs.

The Malaysian Government realising its responsibility to upgrade the quality of life of the poor, has seriously list down its commitment for the RMK-10 period (2011-2015), in which key strategies to provide equitable opportunity to participate in the economy as well as work towards greater socioeconomic inclusiveness among all Malaysians [3]. Poverty in Malaysia is conceptualised and defined as income poverty and measured using a poverty line income to demarcate poor and non-poor households. The poverty line is determined in both absolute and relative terms. Absolute poverty line is calculated based on the income required to purchase a minimum food basket and other basic necessities. The relative concept of poverty stresses income inequality as its fundamental manifestation and is reflected in the definitions of poverty in the lower quintiles of the population, the welfare ratio and the index of poverty. Relative poverty in Malaysia is defined as per capita household income level of less than RM2300 per month with average 
salary of RM1400 that cuts off the bottom 40 percent of the population, also known as the B40 group [3].

As Malaysia enters the last stretch in achieving Vision 2020, the strategic thrust has focused on ICT as an Industry, ICT as an Enabler and ICT for Society [4]. Therefore, to materialise these National Agenda, ICT together with micro sourcing can be used as one of the mechanism to uplift the low household income group. Through micro sourcing, workers have the flexibility of doing work during hours, locations and duration of their own choices. It also provides an additional income to complement existing income. In light of this initiative, the objective of this paper is to propose a micro sourcing development framework for Malaysia

\section{MICRO SOURCING}

Debates about IT outsourcing have lead to the discovery of micro sourcing implementation. As a result of high dependencies in IT project, micro sourcing activities could be emphasized as one of the outsourcing alternatives. If before this, an organization will outsource their IT project to a vendor, but now it can be done through a new mechanism known as micro sourcing.

\section{A. Outsourcing vs.Micro sourcing}

Outsourcing could be defined as an act of delegating or transferring some or all of the information technology related decision making rights, business processes, internal activities, and services to external providers, who develop, manage, and administer these activities in accordance with agreed upon deliverables, performance standards and outputs, as set forth in the contractual agreement [5]. According to [6] outsourcing related to a new process to create new framework involving the relationships of employee/employer. Payroll processing, email, web services and hosting, programming, call centres, and storage area network are examples services that are widely being outsourced [7], [8], [9]. This statement also supported by [10], [11] which has revealed that outsourcing brings competitive advantage, profits and customer satisfaction. It can be concluded, the willingness of an organizations to embark in IT outsourcing is being driven by several factors such as lower costs, faster development cycle, performance assurance and quality, professional and geographically dispersed service and creative and structured leases [12], [13], [14].

Due to the high demand of IT outsourcing, micro sourcing has been taken into consideration for some of the organizations in order to reduce the operational cost, increase the revenue and decrease the employee pressure. Micro sourcing is an effective way to accomplish tedious tasks at a faster rate. Task can be done either online or offline.

Normally, micro sourcing involves large projects that are broken down into micro tasks. These micro tasks are welldefined and then distributed to a group of workers [15]. There were several models proposed for micro sourcing such as FORT framework [16], Structuration Theory [17] and Entrepreneurial model [18]. Research conducted by [18] has proposed to utilize the Structuration Theory in micro sourcing by integrating other ideas related to opportunity research which lead to the discovery of micro sourcing research.
Structuration theory could be defined as entrepreneurial action that is enabled and constrained by conscious selection, imitation, and modification of business "scripts" that occur within social and business structures [18]. Scripts could be used in an environment which needs quick respond. Reference [18] has classified scripts as "legitimate," "powerful," and "competent". Those scripts could be utilized from the organization level to the individual level, which contributes towards the practice of micro sourcing.

Based on the models stated above, it is clearly noted that micro sourcing occurs at individual level and it also facing several challenges that need to be addressed. Hence, emphasize should be given on how does IT supports the micro sourcing activities [19]. Furthermore, like any other IT services, micro sourcing also has to face several key issues that need to be addressed such as data security, agreement between the outsourcer and outsourcees, culture, and communication systems. According to [19], security and intellectual property security, risk and trust between micro sourced employees and contract are the main concern in micro sourcing activities.

\section{B. Global Micro sourcing Industry}

According to Crowdsourcing Industry Report [20], demand in the global micro sourcing industry is driven by start-up and small companies. Collectively they account for over $60 \%$ of the market revenues. Start-up companies drive majority of the revenues in the industry, contributing $39 \%$ of the total revenues. Furthermore, the industry's total revenue grew approximately US\$140.8 million in 2009 and accelerated further to US\$375.7 million in 2011 as depicted in Figure 1.

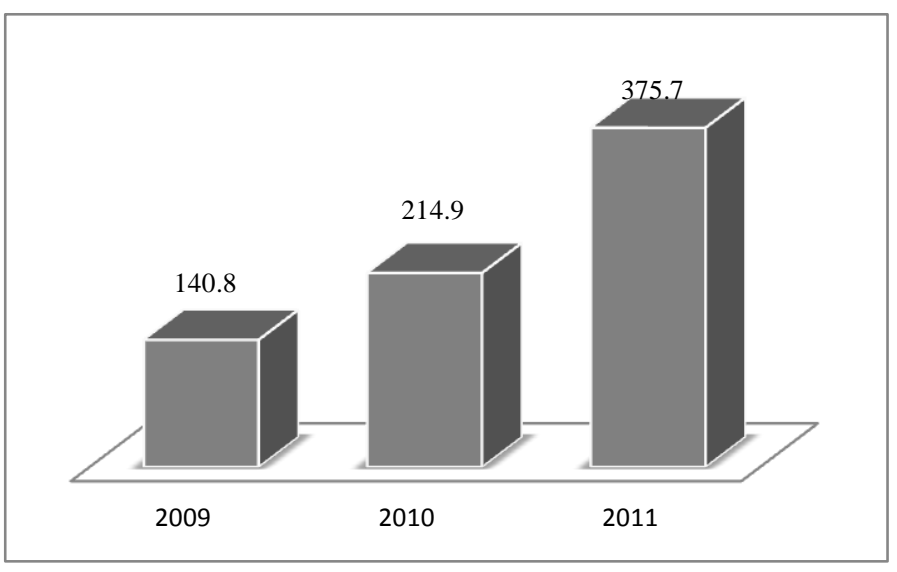

Fig. 1. Global micro sourcing industry’s revenues (US\$ million) [20]

Demand in the global micro sourcing industry as shown in Figure 2 is driven by start-up and small companies. Collectively they account for over $60 \%$ of the market revenues. Start-up companies drive majority of the revenues in the industry, contributing $39 \%$ of the total revenues. Large enterprises with revenue of more than US\$1 billion represented only $8 \%$ of total job providers but contributed $21 \%$ of total revenues due to huge transaction volume. In the global micro sourcing industry, North America and Europe are the largest job providers which contributed to $91 \%$ of jobs collectively. Meanwhile, $41 \%$ of micro workers from North America 
followed by Asia Pacific which is $35 \%$ as depicted in Figure 3. Income for a micro worker vary significantly, depending on type of tasks, number of hours and efficiency in performing the tasks. For example in Figure 4, the top five workers handling micro tasks earn on average US $\$ 500$ per month while the top five workers handling expert and software-based tasks earn on average US $\$ 8,300$ per month. On average, the top five workers from each task category earn US\$4105 per month.

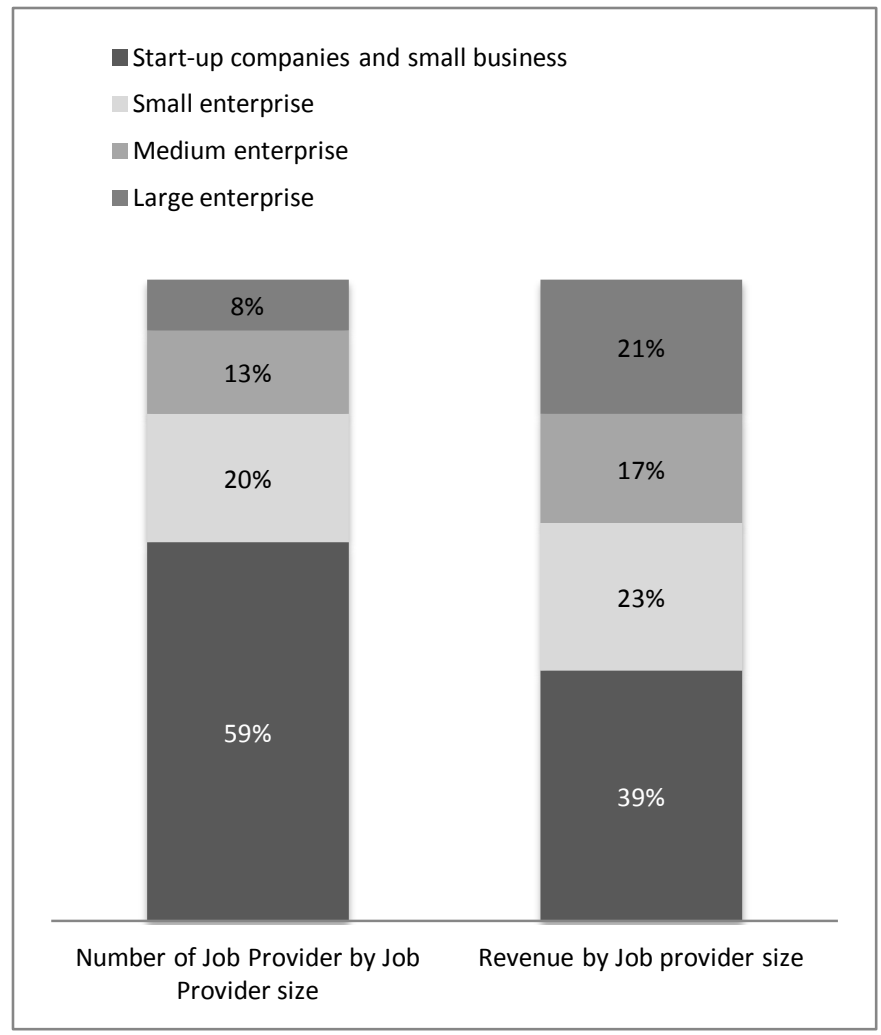

Fig. 2. Number of jb provider and revenue by job provider's size in 2011 [20]

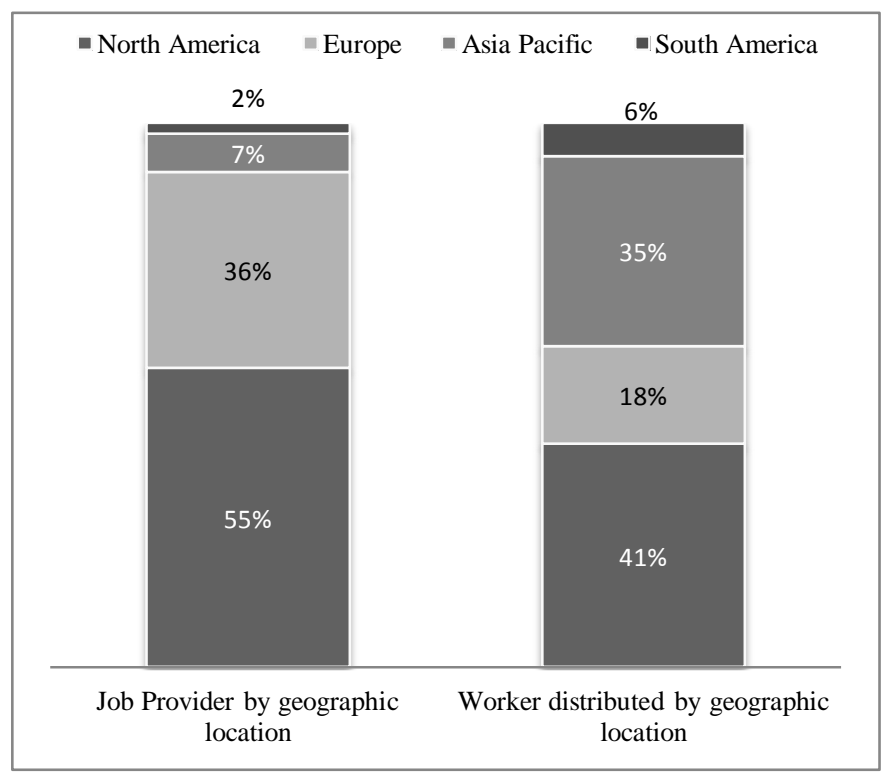

Fig. 3. Job provider and worker by geographic location in 2011 [20]
Platforms are needed to run the software and processes for micro works for use with internal or external micro workers. In the international market, number of platforms has been growing in the past few years. Among the platforms wellknown worldwide are AmazonMechanicalTurk, CrowdFlower, SamaSource, Ushahidi, Micro sourcing and ODesk. AmazonMechanicalTurk was launched in November 2005 and which the requestors are restricted to US-based entities, however the workers can be sourced globally [21]. CrowdFlower was founded in 2007 and uses the MTurk platform to distribute work, but provides its own interface on which work is completed. It also has sophisticated APIs to create and manage works [22]. SamaSource was founded in 2008 and claims to have a dedicated team of remote workers but does not post jobs on a public portal like Mturk [23]. In 2012, Samasource has employed over 3,000 workers from lowincome backgrounds in places as diverse as rural Haiti, informal settlements in East Africa, and peri-urban parts in India, paying out over US\$2 million in wages. At the current growth rate, Samasource expects to pay and train about 20,000 workers by 2017. Ushahidi was founded in 2008 and provides a platform for information collection, visualization and interactive mapping, especially for crises [24]. Micro sourcing is Philippines based company providing traditional outsourcing solutions. Micro sourcing started operations in 2004 and as of July 2011, they employ more than 1500 people working for more than 60 clients from all over the world [25]. Meanwhile, ODesk [26] was founded in 2003 and focus more on long-term work through remote staffing than real micro sourcing.

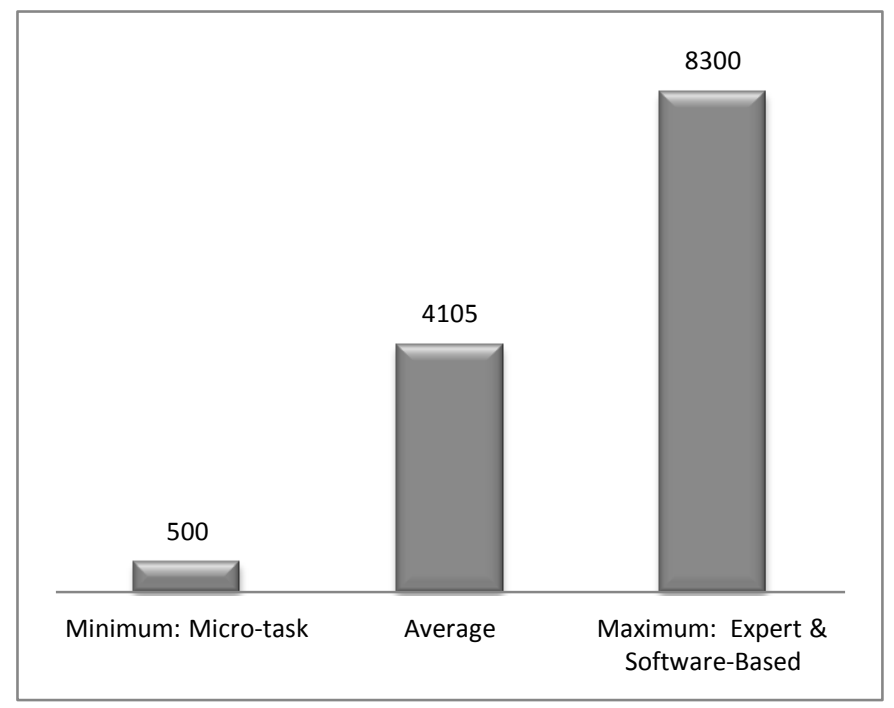

Fig. 4. Monthly earnings(\$USD) of top five workers by task category [20]

\section{Micro sourcing Scenario in Malaysia}

Micro sourcing project is not a green-field project but instead will tap on existing initiatives/ projects under the National ICT Policies. By tapping on existing information and infrastructure, replication and redundancy can be avoided while the impact of these existing initiatives/ projects can be enhanced. Some the existing initiatives/ projects are eGovernment, myGovernment, National Broadband initiative 
and Telecentre Development Program. Opportunities for micro sourcing industry are available in these initiatives. For example, some tasks under e-Government initiatives can be done through micro sourcing. Government agencies manage huge amounts of data under one system for internal and external use. Managing these data requires huge resources that can be minimised through micro sourcing by dividing the tasks required into micro tasks and outsourced them to micro workers. Some of the suitable tasks for micro sourcing are data entry, maintenance of databases, data back-up/ recovery and data protection.

Digitisation service is another suitable task for micro sourcing. Data or document digitisation is a task where data or information are extracted from hard copies (newspapers, books, paper documents, business cards, and periodicals) and soft copies (image/ video/ audio files and analogue signal) which then converted into digital formats. Other Government initiatives such as National Broadband Initiative and Telecentre Development Program meanwhile, could become enablers for the local micro sourcing industry.

Reference [27], the micro sourcing project is targeted to generate RM2.2 billion of income in the micro sourcing industry by 2020 . About $70 \%$ of the income will be generated by the micro workers (employees) as payments for tasks completed. The remaining of the income will be generated by micro sourcing platform operators via profits and salaries. This project is also expected to create 1,425 full time jobs and provide income for 337,000 task workers by 2020 . Another positive impact from this Project will be the value-added benefits to the low income group. Other than earning additional income to complement their existing income, they will also acquire new skills from the training provided.

The existing micro souring business model in Malaysia involved three groups namely Job Providers, Platforms and Micro workers [15], [28]. Job providers will outsource their jobs to micro sourcing platforms. Number of job providers is also quite limited and concentrated within the private sector. In the local market the number of platforms is relatively small and their roles are very limited; as mediator between job providers and micro workers. They advertise the tasks source from job providers and once tasks completed by micro workers; they verify those tasks before submitting them to job providers. Their roles in the local micro sourcing industry are not as wide as international platforms. When a task is advertised on a platform, micro workers will pull the task based on their interests. After the task is completed, the micro worker will submit it together with proof of the completed task to the platform. Once the task is verified as completed by the platform, the macro worker will get paid directly by the job provider. However, the tasks available in the market are not targeted to any specific micro workers and these workers are not given proper training to perform the task. The existing scenario could make the industry unsustainable in the long run.

Study on micro sourcing in Malaysia is very limited since the micro sourcing industry in Malaysia is still at its infancy stage and not properly structured. After analysing the current scenario of local micro sourcing industry, we are proposing development of a "Strategic Framework" to develop micro sourcing industry in Malaysia with focus on the participation of the low income group as micro workers in the industry.

\section{METHODOLOGY}

This study was conducted through documentation review, observations, meetings, workshops and discussions held with relevant stakeholders. Literature review and information gathering were from Digital Malaysia lab report, academic and industry literature, RMK10, EPP annual reports, and market studies.

Focus group meetings and discussion were held starting with a focus group meeting and discussion with Micro sourcing for B40 Implementation Committee (MSIC-B40). MSIC-B40 is responsible to lead and oversee the development of this Project and is also responsible to formulate plans for local micro sourcing growth and identify micro sourcing opportunities for B40. Members of MSIC-B40 come from various non-governmental organisations (NGOs), government agencies, private organisations, universities and distinguished individuals. From these focus group meetings, initial direction of the study was identified and agreed. The research group also participates in the Crowd Business Model Summit (Oct 2012) to identify benchmark and best practices.

Two workshops were held to get the stakeholders engagement and to gather information. The first workshop was held with the objectives to gather information on micro sourcing potentials, opportunities, potential growth and critical enablers from the perspectives of stakeholders. The second workshop was held to discuss the findings and recommendations on the micro sourcing proposed framework and its strategic directions. Participants of both workshops were from MSIC-B40, government ministries and agencies, NGOs and private sectors.

To enrich the data and information gathered, follow up interviews were done with some related government agencies and private sectors. Interviews were also done with local, international platforms and potential job providers from Small Medium Enterprises (SME), Multi National Corporations (MNC) and Public Listed companies. The interviews help to uncover current practices, requirements and challenges in existing Malaysian micro sourcing environment. Interviews with related organisations also help to identify potential partnerships for micro sourcing strategic implementation. The information gathered from all these sources was then compiled and analysed as inputs for this study.

\section{Micro sourcing Strategic Framework}

This study defines micro sourcing as the distribution of well-defined tiny tasks (also referred as micro tasks) to a large group of networked users (micro workers) through the internet. These tasks can be completed under flexible circumstances own time and locations - using basic internet connected devices such as mobile phones, smart phones, tablets, notebooks and personal computers (PCs).

Based on the analysis of the current scenario of local micro sourcing industry, we are proposing a strategic framework for the development of local micro sourcing industry based on five Strategic Thrusts (Figure 5). The Strategic Thrusts are: 
1) Strategic Thrust 1: Harnessing Demand Side (Job Providers) of Domestic and International Market;

2) Strategic Thrust 2: Platform Capacity and Capability Building;

3) Strategic Thrust 3: Leverage and Utilise Existing Infrastructure;

4) Strategic Thrust 4: Uplift and Enhance Capability of the Supply Side (Micro Workers); and

5) Strategic Thrust 5: Instruments to Expedite Growth of Local Micro sourcing Industry.

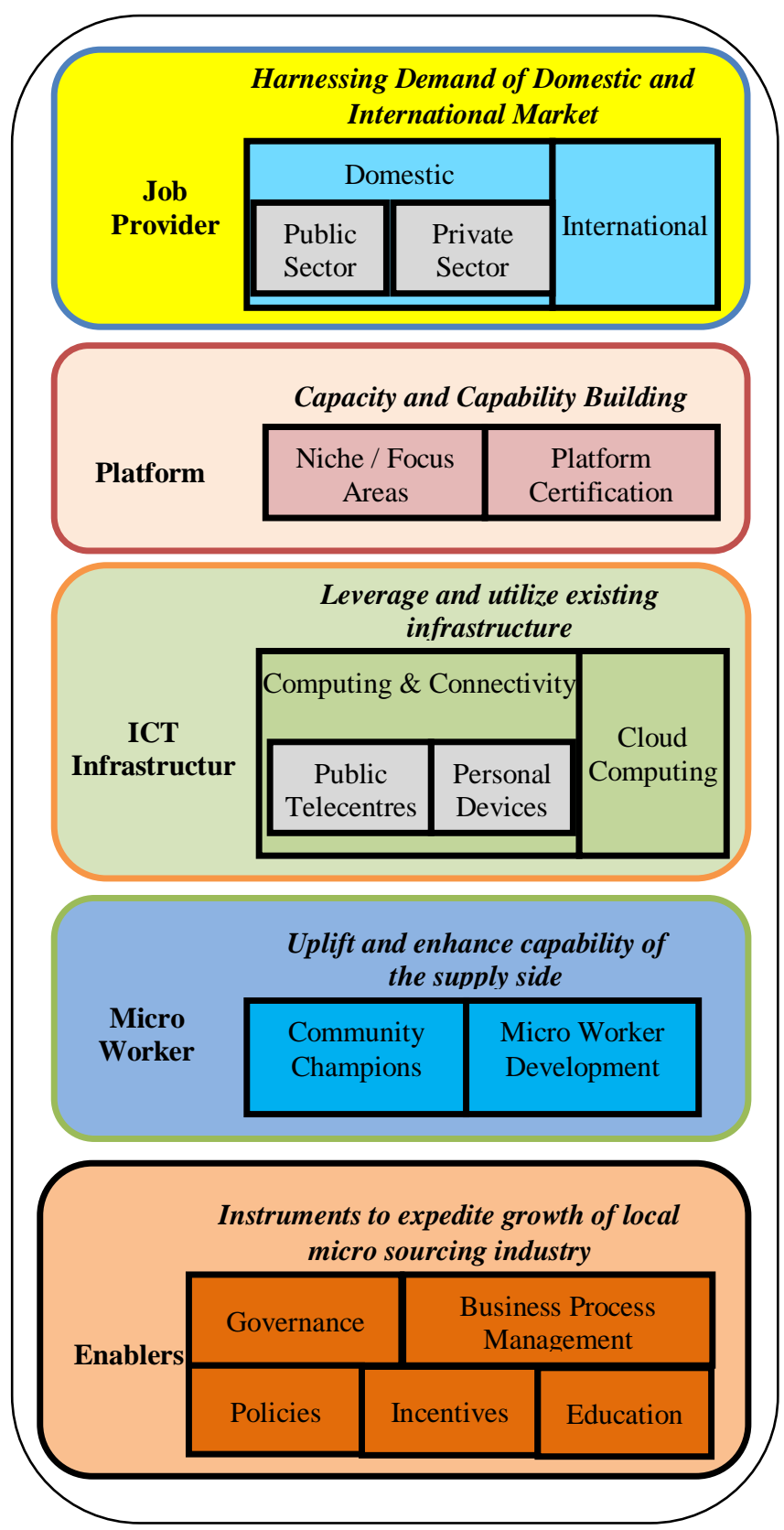

Fig. 5. Proposed micro sourcing strategic framework

The rationale behind the Strategic Framework is to create the proposed Micro sourcing Ecosystem by narrowing or eliminating the gaps identified [15], [28]. Success of the Ecosystem relies on effective roles played by the relevant stakeholders. Thus, this Strategic Framework is intended to be as follows:

1) To provide strategic direction at national level to all stakeholders;

2) To highlight key areas that need to be addressed in order to grow a sustainable micro sourcing industry in the country; and

3) To serve as a guideline in the implementation of programs and plans related to micro sourcing industry development.

Five Strategic Thrusts have been identified as the foundation for the Strategic Framework of the micro sourcing industry development in Malaysia. These Thrusts are based on the SWOT and gap analysis involving the four groups of role players in the proposed micro sourcing industry ecosystem.

\section{B. Strategic Thrust 1: Harnessing Demand Side (Job}

Providers) of Domestic and International Market

Strategy on the demand side (job providers) should focus on capturing local and international demand. The job providers should be from local public and private sectors as well as international firms and organizations.

\section{1) Rationale}

Key to the micro sourcing ecosystem is the volume of micro tasks available in the market. Without enough volume, there will not be enough jobs available for micro workers to sustain the industry ecosystem. There is a wide range of firms/ public agencies, local and international that can be tapped as micro sourcing job providers for local market. The market size for global micro sourcing is estimated to grow to US\$20 billion in 2015 with 780,000 workers. The Malaysian outsourcing industry meanwhile, is predicted to be worth US $\$ 1.9$ billion by 2013.

In general, there is still lack of awareness about micro sourcing among local firms and public agencies. There is a need to promote micro sourcing as a way to lower operation costs especially for Small Medium Enterprises (SMEs) and public sector. On the international front, Malaysia with its diverse population with multicultural background should be promoted as a regional micro sourcing hub to attract international firms outsourcing their micro tasks in Malaysia.

\section{2) Components}

- Public Sector

One of the main sources on the demand side is Federal and State public sectors. Micro sourcing firms could anchored their businesses to public sector's operations, providing them the opportunity to build a track record and scale up their operations before handling wider range of business processes in the private sector. There are large pools of Governments' operations that can be utilised as micro sourcing tasks such as archive digitisation and e-Government platforms.

\section{- Private Sector}

There are many local businesses especially mobile carriers and banks that can provide tasks to local micro sourcing firms. 
For example, there is increasing demand for digitisation of nondigitised records across the private sector. This includes onetime drive to digitised old records and continuous need to digitised new data/ information. Recipients of Government's contracts and concessions can also sub-contract parts of those contracts and concessions to local micro sourcing firms. SMEs are another private sector group that has huge potential as micro sourcing job providers. SMEs can utilise micro sourcing firms' to reduce their operating costs.

Micro tasks are not limited to 'profitable' business operations. Non-profitable operations can also be micro tasked such as activities by non-profit associations and societies. Large corporate also involve in non-profitable tasks under their Corporate Social Responsibility (CSR) activities. There are increasing number of "Triple" bottom line companies that focus on social, environment and financial results, which can utilise micro tasks for their CSR activities.

\section{- International}

Local micro sourcing firms should be encouraged to collaborate with large international business process outsourcing (BPO) firms to tap into jobs from international firms that can be utilised for local micro sourcing market. North American and European firms are the largest job providers for micro sourcing, collectively offering $90 \%$ of job market. Today, the impact sourcing market generates an estimated US $\$ 4.5$ billion in revenues globally, representing $3.8 \%$ of the entire US $\$ 119$ billion BPO industry, and directly employs about 144,000 people across all segments. US\$1.2 billion of these revenues is estimated to be incomes for impact sourcing workers. Share of impact sourcing in total BPO is expected to increase to approximately US\$20 billion in 2015, just over $11 \%$ of total BPO market, and directly accounting for 780,000 jobs. More than US $\$ 10$ billion is expected to be income for impact sourcing workers [20].

\section{Strategic Thrust 2: Platform Capacity and Capability Building}

Platform is important in the micro sourcing ecosystem to link job providers and micro workers. There should be enough platforms with diverse niche and focus areas that suit different key target groups of micro workers. These platforms should also be accredited to make them competitive.

\section{1) Rationale}

As there is no boundary in digital world, local micro sourcing platforms should be at the highest level of capacity and capability to compete with international platforms. Competitive platforms in local micro sourcing ecosystem require skilled and experienced talents that can design reliable, safe and diverse platforms.

Currently, there is no established national minimum standard and certification program for micro sourcing platforms. Without this standard and certification, we will not be able to promote Malaysia as a micro sourcing industry hub. Standard and certification will not only ensure platforms adhere to services of the highest quality but also ensure there are enough platforms suitable for the key target groups of micro workers.
Targeted micro workers have different competent levels and skills. Therefore, available platforms should be as diverse as possible to cater for these differences.

\section{2) Components}

- Niche/ Focus Areas

Each platform is specialised based on the type of task completed. These types of tasks can be categorised into ICT enabler or ICT related categories. ICT enabler refers to the use of ICT as an enabler to advertise a job or obtaining a task. ICT enabler does not require ICT to complete the tasks, but instead used to communicate the task to the workers. On the other hand, ICT related tasks refer to types of work that require ICT to complete the tasks. ICT related tasks include ideation-based tasks, knowledge-based task, expertise-based tasks and micro task.

Diverse platforms should be made available with different niche/ focus areas to cater for different types of targeted micro workers. Targeted micro workers have different competency levels and skills. Diverse platforms will allow wider pool of workers to participate in the micro sourcing industry.

\section{- Platform Certification}

Platform certification is important to ensure platforms' credibility. It provides guidance to better integrate the application process into micro sourcing ecosystem and ensures the quality of functional design incorporated into the micro sourcing platform. This guidance includes information on the technical and business processes, implementation of platform requirements, and certification requirements for a micro sourcing platform. A micro sourcing platform that has gone through certification processes means that it has met or exceeded the standards required. The certification processes should cover a platform's operations, security, performance, and resources to ensure the platform's capabilities and services

\section{Strategic Thrust 3: Leverage and Utilise Existing \\ Infrastructure}

Existing infrastructure should be leveraged and utilises to reach out targeted groups of micro workers and reduce cost of platforms. Existing public telecentres can be used as micro tasks centres for targeted micro workers. In addition, targeted micro workers can also be assisted to have personal devices for micro tasks usage. Existing cloud computing infrastructure meanwhile, can provide flexibility, lower cost and improved scalability for platform providers

\section{1) Rationale}

Government has invested in various programs in rural areas, as well as selected urban areas to increase people's access to the Internet. These programs, such as setting up public telecentres and building telecommunication towers, are intended to reduce the digital divide between rural and urban areas, and also increase access to Internet for the under-served sections of the society. Currently there are 2,477 telecentres for different target groups that can be used as micro tasks centres to train micro workers as well as job locations for micro workers. However, proper coordination is needed to ensure that these telecentres are coordinated and managed properly to 
ensure that they are properly utilised for the benefits of targeted micro workers.

Other than telecentres, personal devices such as mobile phones, tablets, Personal Digital Assistants (PDAs) and smart phones are among essential connectivity infrastructures to be available among B40 micro workers. However, since most of B40 cannot afford to have smart devices with Internet connection, there is a need to leverage on existing public telecentres.

Cloud computing is another existing IT infrastructure that can be utilised, especially with the increasing usage of personal mobile devices by micro workers. Cloud computing allows transfer of information and functionality between users and systems via mobile devices. Platform operators can optimise their IT infrastructure through cloud computing by leveraging on various enterprise-level applications provided by many MSC status companies. Utilising existing infrastructure will lower operating cost of platform operators and thus, make local platforms more competitive.

2) Components

- Computing and Connectivity (through Public Telecentres and Personal Devices)

In order to reach the targeted micro workers, computing infrastructure and connectivity are important. There are two models that can be utilized:-

○ usage of personal computing devices for individuals to access to Internet and complete their tasks; and

○ usage of public telecentres as distribution centres for micro workers to complete their tasks.

\section{- Cloud Computing}

Cloud computing infrastructure allows platform operators to reallocate their IT operational costs from infrastructurerelated costs to other important costs such as platform designing. In addition, with applications hosted centrally, updates can be released without the need for platform operators to install new software. In a business model using cloud computing, platform operators are provided with access to application software and databases hosted at a centralised server. Cloud computing allows platform operators to get their applications up and running faster, with improved manageability and less maintenance, and also enables them to rapidly adjust their resources to meet fluctuating and unpredictable business demand. Cloud-based applications will also make it easier for micro workers to access platforms via web browser from a desktop or mobile application.

Using cloud computing, platform providers will have the opportunity to leverage enterprise-level applications and development without the associated upfront capital expenditure pinch or complex IT roll-out. Cloud computing may also be more flexible in developing new micro sourcing applications because the cloud includes middleware, and users are not limited to one server or one data centre. Cloud computing also has been proven to be very scalable, and can overcome technical fault or maintenance related downtime.

\section{E. Strategic Thrust 4: Uplift and Enhance Capability of the Supply Side (Micro Workers)}

Supply side in a micro sourcing industry ecosystem is not only about the numbers of micro workers available but also the capability of these micro workers and the quality of the micro tasks that they completed. Investment in training for micro workers' development is important to ensure high quality of labour supplies in the ecosystem. Community Champions should be groomed to engage these targeted micro workers.

\section{1) Rationale}

Skills training are necessary to ensure sustainability of any industry. This is particularly pertinent when considering the employability gap that is being seen today, where graduates can be deemed as non-employable due to skills gaps. As the proposed micro sourcing industry ecosystem is targeted at certain groups of micro workers especially the B40 group, skills training for these groups is a must since $52.3 \%$ of people in the B40 group have no education certificate and most of them have low to moderate competency in computer and Internet skills, as well as English proficiency [15].

Programs and activities to enhance capability of these targeted micro workers should involve organisations/ agencies that have direct contact with these groups. NGOs such as Yayasan Basmi Kemiskinan (YBK) and Yayasan Pembangunan Islam Malaysia (YAPEIM), and Government agencies such as Regional Development or Kementerian Pembangunan Luar Bandar dan Wilayah (KPLBW), Jabatan Kemajuan Masyarakat (KEMAS) and Pusat Zakat Selangor (PZS) should be roped in as they are well-verse with these targeted groups' environment. These organisations/agencies should be groom as Community Champions to engage these targeted groups into the micro sourcing industry ecosystem.

Funding for these programs and activities should come from the Government or sourced from private sectors' contributions as most these targeted micro workers cannot afford to pay for them.

\section{2) Components}

- Community Champions

Community Champions should be created within the micro sourcing ecosystem to engage participation of targeted micro workers from specific community. Platform owner should identify the Community Champion for a distribution centre and work together closely in engaging these micro workers. Candidates for Community Champions most preferably are organisations/ societies/ individuals that have established relations with the community. Platform firms will be the one to aggregate the tasks while the Community Champions will be responsible to maintain the infrastructure at the distribution centres.

\section{- Micro Worker Development.}

To support the sustainability of the Micro sourcing Ecosystem, targeted micro workers especially the B40 group need to be continuously trained. Among crucial training required are ICT-related courses, communication skills and personality development courses. Training, skills and 
knowledge development must be on-going and therefore require considerable investment.

\section{F. Strategic Thrust 5: Instruments to expediate Growth of Local Micro Sourcing Industry}

An effective Micro sourcing Ecosystem requires proper governance. As with any established industry, proper monitoring or regulatory bodies are required to monitor fair play, enforce equitable standards, and prevent exploitation of stakeholders, especially micro workers. Government's policies and incentives are also important to kick start the micro sourcing industry development.

\section{1) Rationale}

The micro sourcing industry in Malaysia is still at its infancy stage. Therefore, lots of questions arise from potential role players from the four groups in the ecosystem - Job Providers, Micro Workers, Platforms Providers and Enablers on the sustainability and security of the industry. Proper regulatory and monitoring frameworks to govern the industry will provide confidence to public and private sectors, organisations and individuals to participate in the industry. Proper regulatory and monitoring frameworks will also create a healthy ecosystem with proper marketing, enforcement, security and documented procedure.

The Government has important role to play to expedite industry's growth. Government's incentives are crucial as there will be lack of private investment at the initial stage. Potential local job providers need to be attracted, potential micro workers need to be trained, and potential platform developers need to be assisted to compete with international platforms. Certain existing incentives need to be reshaped to suit micro sourcing industry's requirement. Government's policies also need to be designed to support the industry's growth.

The micro sourcing industry is still lacking skilled/ experienced talents across the ecosystem. There is a need to develop skilled and experienced talents as well as project management and business development teams to support micro sourcing platforms. Therefore, there is need to incentivise training and skilling of talents across the industry to ensure industry sustainability.

Engagement with professional organisations, particularly those in the field of micro sourcing and outsourcing advisory services is important to spread awareness and understanding of what micro sourcing industry can offers. These organisations can provide leadership and promote sharing of solution and best practices, as well as spur new business process management and innovation.

\section{2) Components}

\section{- Governance}

The micro sourcing industry ecosystem involves many stakeholders with their own agenda and objectives. As with any established industry, proper monitoring or regulatory bodies are required to supervise fair play, employ equitable standards, and prevent the exploitation of its players, particularly the employees.
A proper governance structure is required to monitor payment, conditions, and competition, as well as to uphold the objective of micro sourcing industry as a mean to alleviate disadvantaged from poverty.

\section{- Policies}

Competing effectively in the micro sourcing market place requires Government's role to create and introduce business friendly legal systems, policies and industry support mechanisms. For example, the Government could impose uniform restrictions on hiring foreign workers in an effort for private sectors to find ways in hiring local workers, including via micro sourcing. The Government could also provide leadership in the industry by outsourcing its non-core tasks and introducing micro sourcing-related tasks in its procurement policy. Other enabling policies could also be developed such as policies on micro sourcing self-regulation, telecentres opening hours and payment mechanism.

\section{- Incentives}

The Government can also promote micro sourcing industry through incentives. Domestic outsourcing can be encouraged by incentivising organisations that provide outsourced services. Government can foster investment in the industry by providing special incentives to firms who invest in programs and activities that benefit marginalised and disadvantaged households such as those to engage participation of the B40 group in the micro sourcing industry. Guideline on homeworking could be strengthened to encourage job providers to hire more micro worker especially the B40.

- Business Process Management.

New business process management that supports micro sourcing initiatives should be promoted. All relevant stakeholders such as Government agencies, private sectors, SMEs and NGOs need to be engaged and educated on micro sourcing and how to formulate a micro sourcing strategy. Micro sourcing pilot projects have to be monitored to ensure they have the necessary support and backing from all relevant stakeholders within the ecosystem.

\section{- Education}

All relevant stakeholders in the industry require continuous education and trainings. In addition, awareness programs are required from time to time to educate the general public about the industry. The industry requires high skilled workers to manage micro sourcing platforms and therefore, training/ educational programs should be encouraged. Linkages between industry and institutes of higher learning (IHLs) are essential to ensure continuous supply of skilled talents into the industry.

For micro sourcing industry to grow in Malaysia, all relevant stakeholders will need to be aware of the micro sourcing business processes. The role of workplace is changing with technology development, combined with an increasingly cross-generational and distributed workforce, challenging traditional concepts of the workplace. Thus, the implementation of the Strategic Framework require strong governance and leadership, mandated actions where 
appropriate, enforcement via spend controls, and monitoring and reporting.

\section{CONCLUSION}

As highlighted earlier, jobs for local micro sourcing industry would be sourced from local and international job providers. Contrary, awareness level of micro sourcing is still low among potential local job providers. In addition, potential job providers from the public sector have concerns on the local micro sourcing mechanism such as data confidentiality and payment mechanisms. These issues need to be adressed to get their confidence in the industry. As a pre-requisite to the local micro sourcing industry development, potential job providers in public and private sectors should have a thorough understanding, readiness, and awareness of the industry. Other than local job providers, efforts must also be made to capture jobs from international market through international platforms as well as international BPO service providers.

As in any new industry, support from the Government is very important in developing local micro sourcing industry. Each Strategic Thrust involves Government's participation in different capacity. Supports from other ministries, agencies and other divisions in public sector are nevertheless important in making this project and the micro sourcing industry in general a success. This project cuts across multiple sectors and thus, requires different types of Government support from different ministries and agencies. Other stakeholders also have to perform their roles in to ensure the effectiveness of the proposed Strategic Framework. With full support from these stakeholders, this industry would be able to achieve its true economic potential and this project would be able to help improve the socioeconomic status of the low income group in Malaysia.

\section{References}

[1] Prahalad. C.K., "The fortune at the bottom of the pyramid: eradicating poverty through profit". Upper Saddle River, NJ: Wharton School Publishing, 2004.

[2] Heeks, R., "Where next for ICTs and international development?. In ICTs for Development. Paris". Organisation for Economic Co-operation and Development (OECD) 2009, pp. 29-74.

[3] EPU, "Economic Planning Unit, Tenth Malaysia Plan 2011-2015". Prime Minister's Department, Putrajaya , 2010.

[4] Ling, R., Chan, H., Choon, L.S., Singh, D and Lim, Victor, "Special study: MSC Malaysia 2.0 state ICT blueprint: Negeri Sembilan”, 2010

[5] Dhar.S and Balakrishnan, B., "Risks, benefits and challenges in global it outsourcing: perspectives and practices", Journal of Global Information Management, Vol. 14, Issue 3, pp. 59-89., September 2006.

[6] Kishore, R., H. R. Rao, K. Nam, S. Rajagopalan et al., " A relationship perspective on it outsourcing, "Communications of the ACM (46) 12, pp. 87-92. 2003

[7] Dhar.S, "From outsourcing to cloud computing: evolution of it services, IEEE Int'l Technology Management Conference, Vol. 11, 2011, pp. 434$438 "$
[8] Arshad, N.H., Yap,M.L., Mohamed, A., and Affandi, S., "Inherent risks in ICT outsourcing projects". Proceedings of the $8^{\text {th }}$ WSEAS International Conference on Mathematics and Computers in Business and Economics, Vancouver, Canada, June, 2007, pp.141-146.

[9] Arshad, N.H., Yap,M.L., and Mohamed, A., "ICT outsourcing: inherent risks, issues and challenges". WSEAS Transactions on Business and Economics, Iss 8, Vol. 4, 2007, pp.117-124.

[10] Ang, S. and Straub, D.W., "Production and Transaction Economies and IS Outsourcing: A Study of the U.S. Banking Industry" MIS Quarterly, Volume 22, No. 4. 1998.

[11] Dibbern, J., Goles, T., Hirschheim, R., \& Jayatilaka.,"Information systems outsourcing: A survey and analysis of the literature", The Data Base for Advances in Information Systems, 35(4), 2004, pp. 6-102.

[12] Arshad, N.H., Hanapi, H., and Buniyamin, N., "IT outsourcing and knowledge transfer in Malaysia". Proceeding of $2^{\text {nd }}$ International Congress on Engineering Education, Kuala Lumpur, December, 2010, pp.19-21.

[13] Bahli, B. and Rivard S.,"The information technology outsourcing risk: a transaction cost and agency theory-based perspective". Journal of Information Technology, vol. 18, no. 3, 2003, pp. 211-221.

[14] King, W.R. \& Malhotra, Y., Developing a framework for analyzing IS sourcing. Information \& Management, 37, 2000, pp. 323-334.

[15] Arshad, N. H., Salleh, S.S., Aris, S.R.S, Janom, N., Mastuki, N., "Micro sourcing: The SWOT analysis on the demand, supply and platform". Science and Information Conference (SAI), October, London, 2013. "inpress".

[16] Kishore, R., H. R. Rao, K. Nam, S. Rajagopalan et al., " A relationship perspective on it outsourcing, "Communications of the ACM (46) 12, 2003, pp. 87-92.

[17] Giddens, A., "The Constitution of Society: Outline of the Thoery of Structuration", University of California Press, Berkely and Los Angeles,1984, pp.1-28.

[18] Chiasson, M. and Saunders, C.,"Reconciling diverse approaches to opportunity research using the structuration theory," Journal of Business Venturing (20), 2005, pp. 747-767.

[19] Obal, L., "Microsourcing - "Using Information Technology to Create Unexpected Work Relationships and Entrepreneurial Opportunities". Communications of the Association for Information Systems. Vol (24), No 1., 2009.

[20] Crowdsourcing Industry Report. "Enterprise Crowdsourcing: Market, Provider and Worker Trends", February 2012, Massolution. URL (accessed 20 September 2012), http://www.massoultion.com

[21] AmazonMechanicalTurk, (accessed 29 Septembrer 2012), https://www.mturk.com/mturk/.

[22] CrowdFlower, (accessed 29 September 2012), http://crowdflower.com/.

[23] SamaSource, (accessed 29 September 2012), http://samasource.org/.

[24] Ushahidi, (accessed 29 September 2012), http://www.ushahidi.com/).

[25] Micro sourcing, (accessed 29 September 2012), http://www.micro sourcing.com/.

[26] ODesk, (accessed 29 September 2012), https://www.odesk.com/.

[27] Multimedia Development Corporation Sdn. Bhd. (MDeC), 2012, Digital Malaysia Lab Report.

[28] Salleh, S.S., Arshad, N. H., Aris, S.R.S, Janom, N., Mastuki, N., "Formulating Cohesive Digital Ecosystem of Micro Sourcing Business Process in Malaysia". Science and Information Conference (SAI), October, London, 2013. "in-press". 